$30 \%$ for the latter. The purpose of this article was to determine these factors by qualitative research, according to medical students points of view.

Methods It was a qualitative study using semi-structured interviews. The analysis was done according to Grounded Theory.

Results 12 medical students were interviewed. They expressed difficulties at work and positive factors. Three major themes were identified in selective coding: occupational factors, 'study' factors and individual factors. All themes were both a source of well-being and ill-being according to the situations specified in the results.

Conclusion Studying medicine includes positive and negative aspects. Abandonment issues, lack of recognition and insufficient coaching emerge from our study. These results open lines of thought on the ways of improving formation of medical students.

\section{THE INFLUENCE OF OCCUPATIONAL MEDICINE PROGRAM IN MEDICAL STUDENTS' ATTITUDE TOWARDS THIS SPECIALTY}

Armand Rajnoveanu*, Razvan Ionut, Maria Barsan, Andreea Socaciu, Marilena Oarga. Iuliu Hatieganu University of Medicine and Pharmacy, Dept. of Occupational Medicine, ClujNapoca, Romania

\subsection{6/oemed-2018-ICOHabstracts.284}

Introduction Occupational medicine in Romania is not one of the first choices for residency training programmes and there are medical schools with no or just an optional educational program in this specialty for medical students. We tried to estimate the influence of such a program in changing students' attitude towards our specialty.

Methods We used the 18 items questionnaire developed by Smits and Verbeek and published in Occupational Medicine Journal in 2015, which was applied in its original form (English version) on 141 fourth-year medical students before and after their educational program in occupational medicine. Data was collected in a Microsoft Excel Datasheet and analysed using statistical functions (average, sum, standard deviation, ttest paired samples, and 0.05 statistical significance threshold was used). Items were collapsed in three scales according to the authors (a career in occupational medicine - 6 items, occupational medicine as an interesting specialty - 11 items and role and position of the occupational physician - 1 item). Results For the first scale the mean score before was 17.35 and 16.87 after the educational program (0.48 difference and $\mathrm{p}=0.082)$. The second scale had a mean score before of 42.97 points and 43.78 after ( 0.81 difference and $p=0.010)$, and the third scale, 3.39 before and 3.58 after (difference of 0.19 and $\mathrm{p}=0.048)$.

Discussion Results showed us scores which are comparable with the ones described in the original paper. In our research the educational program didn't reveal a positive effect in students attitude regarding choosing a career in occupational medicine (the score decreased but not statistical significant). A positive response was noticed in changing their attitude about occupational medicine as a specialty (higher score after and statistical significant) and also in the awareness of the necessity of independence of the occupational physician from the employer.

\section{5 \\ NATIONWIDE OCCUPATIONAL MEDICINE TRAINING PROGRAM IN THE FINNISH INSTITUTE OF OCCUPATIONAL HEALTH}

Jari H Stengård* ${ }^{*}$ Eva Helaskoski. Finnish Institute of Occupational Health, Helsinki, Finland

10.1136/oemed-2018-ICOHabstracts.285

Introduction Teaching of occupational medicine is an integral part of the training of occupational health specialists. This training takes place in Finnish Institute of Occupational Health Institute (FIOH) in Helsinki and its four regional offices. A challenge is that instructors in different regions have different skills and their resources are different. Here we present our new, nationwide occupational medicine training program, which has recently piloted and launched. It consists of six modules that correspond to the learning objectives given in university curricula. Each module includes lectures, workshops and self-study but also practical tasks, such as workplace visits, outpatient work and literature search. In teaching we use a web-based learning platform.

Methods The program was developed in collaboration with a selected group of trainees and all instructors in Helsinki and in all regional offices of FIOH. Feedback from instructors and trainees was collected by employing a web-based questionnaire and face-to-face discussions.

Results Feedback from instructors and trainees has been positive. The following things are considered as benefits of the new program:

- trainees receive same kind of training, regardless of locations where they specialise,

- they can view lectures later on video and

- they can discuss with other trainees and instructors in other areas, and

- instructors can take advantage of each other's material,

- we can employ modern pedagogic theories and teaching methods and

- instructors can more easily communicate with their trainees.

Discussion We had a need to reform and unify occupational medicine training at $\mathrm{FIOH}$. Participation of students and all regional instructors was central to the success of the program development. Our program has been well received by trainees and instructors. Web-based learning platform makes it possible for us to take advantage of instructors' different skills and to use new pedagogical theories and methods in our teaching

\section{GROUP EXPERIENTIAL INTERVENTION IN GREEK HEALTH PROFESSIONALS FOR THE CONFRONTATION OF MOBBING}

${ }^{1}$ Koinis Aristotelis, ${ }^{2}$ Velonakis Emmanouil, ${ }^{3}$ Tzavella Fotini, ${ }^{4}$ Tziaferi G Styliani. ${ }^{1}$ Clinical Psychologist, MSc, PhD(c), Psychiatric Sector, General Hospital of Argolida/Dep. of Nursing Laboratory of Integrated Health Care, University of Peloponnese Sparti, Greece; ${ }^{2}$ Professor of Public Health, Faculty of Health Sciences NKU Athens, Greece; ${ }^{3}$ Lecturer in Sociology of Health, University of Peloponnese, Sparta, Greece; ${ }^{4}$ Assistant Professor of Community Nursing, Dep. of Nursing Laboratory of Integrated Health Care, University of Peloponnese, Sparta, Greece

\subsection{6/oemed-2018-ICOHabstracts.286}

Introduction There are many ways to tackle with mobbing, with mainstream counselling and psychological support either 
on a group or an individual level. Group experiential interventions focus on the infected worker.

Aim The purpose of such intervention programs will be the relief and emotional discharge of the symptoms of mobbing in workers in a hospital sector.

Material and methods In the focus groups will participate 40 health professionals voluntarily, in the intervention part of a study's protocol that is in process referring to a Doctoral Thesis in a Greek University. Sessions will take place in a public hospital, twice a week for 4 hours. 13 sessions will be held, organised in 4 groups of 10 people each. Interpersonal supportive psychotherapy treatment plan including techniques such as taking an individual-social-family history, role playing, drama therapy and cognitive behavioural therapy in a group therapeutic milieu. In particular, participants by playing roles, people relive the traumatic events, express their feelings, and the therapist helps to reduce negative emotions and to make adaptive beliefs. Also through the techniques of drama (mirror, chairs, narrative counselling, the individual expresses the history of his life in order to understand, evaluate and reassess his experiences.) The therapy does not aim at stirring internal psychological processes but illuminating the particular problem of a person-society relationship. The therapist's mission is to help the participants to overcome the problem. Through the techniques of cognitive behavioural therapy, participants will recognise their dysfunctional thoughts, process their feelings and behaviours about mobbing and with the help of the therapist will try to 'change' the way of thinking about their working lives.

Results This therapeutic approach will be used in order to strengthen the individuals self esteem, self appreciation and make them aware of their negative automatic cognitions and to produce data that may solve the problem of mobbing in their workplace.

Discussion The study expects to record accurately the size of the problem and indicate the appropriate tools for the implementation of interventions (prevention and awareness programs) both by mental health specialists and the decision makers and to enrich the scientific literature.

\section{EVALUATION OF EDUCATION OF SPECIALIST OCCUPATIONAL HEALTH PHYSICIANS IN THE PERIOD 2009-2013 IN FINLAND}

Jarmo Heikkinen*, Kimmo Räsänen. ,2Faculty of Health Sciences, Institute of Public Health and Clinical Nutrition, University of Eastern Finland, Kuopio campus

10.1136/oemed-2018-ICOHabstracts.287

Introduction A nationwide external quality evaluation aimed to identify strengths, good practices and areas in need of development.

Methods The enhancement-led four-phase evaluation process included a self-evaluation report by the universities; evaluation interviews and visits by the evaluators; an evaluation report; and a feedback seminar. The evaluation focused on the management and planning of education and the definition of learning outcomes and the learning philosophy; education resources and support and pedagogical training; the constructive alignment of education; and the continuous development of education.

Results Key strengths included good cooperation between units, pedagogical training of the trainers, investment in web- based learning and the use of previous evaluations in the development of education.

Changes in working life, the upcoming reform of specialist medical education and the continuity of funding were seen as external challenges.

Areas needing development included clarifying of the learning philosophy, broadening the learning outcomes to cover competences, achieving higher visibility, expanding and diversifying practices for learning assessment and feedback. Reflection practices were recommended to support interaction skills, professional growth and the promotion of development skills. Advancing pedagogical training of trainers was suggested. Genuinely interactive virtual learning was emphasised. Increasing the throughput of students and promoting interest in the specialty at the basic studies stage were recommended. The research-based and international approach in developing education was encouraged.

Discussion After the report the learning philosophy was clarified in the new curriculum, reflection was included in the logbook and a project to develop evaluation of the learning outcomes as competencies and entrustable professional activities started. A pedagogical web-based course and a pedagogical guide book for trainers were published. The specialty has worked vigorously on the external challenges, too.

High quality education is essential in occupational health care. An external evaluation of education may substantially help to meet the challenges of quality education.

\section{THE INTEGRATION OF OCCUPATIONAL HEALTH AND SAFETY INTO EDUCATION - ENETOSH'S WEALTH OF EXPERIENCE}

${ }^{1} \mathrm{U}$ Bollmann ${ }^{*},{ }^{2} \mathrm{R}$ Gründler, ${ }^{3} \mathrm{M}$ Holder. ${ }^{1}$ Institute for Work and Health of the German Social Accident Insurance (DGUV), Dresden, Germany; ${ }^{2}$ WissensImpuls, Dresden, Germany; ${ }^{3}$ British Safety Council (BSC), London, Great Britain

\subsection{6/oemed-2018-ICOHabstracts.288}

Introduction The results of an empirical study which analysed good-practice examples of integrating occupational health and safety into education are presented. The good practice was collected by the European Network Education and Training in Occupational Safety and Health (ENETOSH) over the last ten years and published on www.enetosh.net. The study was done in response to a request made by the International Labour Organisation (ILO) in order to make empirical statements on trends and promising models for integrating health and safety into education. Methods From 756 projects a representative sample of examples was chosen for each level of education (kindergarten/ school, initial vocational education and training, higher education and continuing vocational education and training). A category-system was developed which is based on the success principles of the settings-based approach as specified by the World Health Organisation (WHO). 83 examples were categorised and analysed. The study consists of a qualitative analysis as well as a statistical analysis. Within the qualitative part of the study interviews with project owners and leading experts in the field are carried out to gain experience of how to put the categories into practice.

Result The study provides a comprehensive evidence-base of practices of good models concerning mainstreaming occupational health and safety at all levels of education. The study facilitates better access to practices of good models for practitioners and 